\title{
Genetic Diversity of Pyrenophera tritici-repentis Isolates, the Causal Agent of Wheat Tan Spot Disease from Northern Iran
}

\author{
Avin Aghamiri 1, Rahim Mehrabi ${ }^{2, *}$, Reza Talebi ${ }^{3}$ \\ ${ }^{1}$ Department of Microbiology, Sanandaj Branch, Islamic Azad University, Sanandaj, Iran \\ ${ }^{2}$ Agricultural Research, Education and Extension Organization (ARREO), Seed and Plant Improvement Institute, Karaj, \\ Iran \\ ${ }^{3}$ Department of Agronomy and Plant Breeding, Sanandaj Branch, Islamic Azad University, Sanandaj, Iran \\ ${ }^{*}$ Corresponding author: Rahim Mehrabi, Cereal Research Department, Seed and Plant Improvement Institute, Karaj, Iran. Tel: +98-2636701106, Fax: +98- \\ 2632709405, E-mail: Rahim.Mehrabi@gmail.com
}

Received: December 29, 2014; Revised: April 15, 2015; Accepted: May 26, 2015

Background: The tan spot disease of wheat caused by Pyrenophera tritici-repentis has become a major disease in most wheat growing areas worldwide.

Objectives: Here we used ISSR and RAPD markers to study the genetic diversity of 34 P. tritici-repentis isolates collected from North of Iran.

Materials and Methods: The leaves having the typical symptoms of tan spot disease were collected and after fungal isolation, purification and identification, DNAs were extracted. After PCR amplification using each primer, PCR products were run in agarose gels, and the resulting bands were scored. Cluster analysis was performed using Un-Wighted Nighbor Joining method.

Results: A total of 178 reproducible bands were scored. Out of which $115(65 \%)$ were polymorphic corresponding to an average of 8 polymorphic bands per primer. The average PIC values for ISSR and RAPD markers were 0.38 and 0.43 , respectively. A high degree of genetic variability among Iranian $P$. tritici-repentis isolates was identified. Cluster analysis based on un-weighted neighbor-joining method using the combined molecular data revealed five distinct clusters. The results from the cluster analysis indicated that the genetic similarity among the Iranian $P$. tritici-repentis isolates could be partly explained by geographic origins where the isolates were collected.

Conclusions: Genetic variability of $P$. tritici-repentis along with relatively high level of geographic diversity observed in this study may suggest longer evolutionary period for the isolates from the Middle East, wheat center of origin, as opposed to other places.

Keywords: Cluster analysis; Drechslera tritici-repentis; ISSR and RAPD markers; Genetic variability

\section{Background}

The fungus Pyrenophera tritici-repentis (Died.) Drechs. [anamorph: Drechslera tritici-repentis (Died.) Shoem] is the causal agent of wheat tan spot. It has become a major disease in most wheat growing areas worldwide (1). Under favorable environmental condition, the disease causes significant economic losses up to $50 \%$ of wheat production, particularly where susceptible cultivars are planted (2). The economic impact of tan spot disease is increasing due to the introduction of high yielding susceptible cultivars that are improved for resistance to other biotic and abiotic stresses. In addition, reduced or zero-tillage practices, shorter crop rotations and continuous wheat cultivation favor pathogen overwintering on plant residues.
The pathogen overwintering allows the formation of the teleomorph stage. This stage not only provides primary inoculum of $P$. tritici-repentis, but also increases genetic recombination developing more races (3-4).

In Iran, $P$. tritici-repentis has intensified recently in some wheat-growing areas, mainly because of the introduction of susceptible wheat cultivars of International Maize and Wheat Improvement Center (CIMMYT) that have been planted in a monoculture fashion. As a result, severe epidemics have occurred in major wheat-growing provinces, including Mazandaran and Golestan (4). Accordingly, development of resistant wheat cultivars to replace the susceptible ones seems inevitable.

P. tritici-repentis is a homothallic fungus that read- 
ily enters into generative phase, allowing the fungal population to recombine and generate new races (2). It was shown that sexual reproduction plays a significant role in genetic variability of fungal pathogens, resulting in increased biological fitness (5). This enables the fungal pathogens to rapidly evolve to overcome resistance genes as a response to selection pressure imposed by resistant cultivars, which has been frequently reported in many pathosystems (6). Therefore, study on the genetic variability of plant pathogen populations could likely lead to better management of disease in agricultural ecosystems and is required for proper decisions in breeding programs (7).

During the past two decades, molecular markers have been extensively used to study the population structure of many fungal pathogens $(8,9)$. However, to date, limited information is available on the molecular biodiversity and genetic structure of $P$. tritici-repentis populations. The pathogen is reported in many wheat growing regions around the world, but so far genetic diversity of limited populations have been studied. These populations consisted of the isolates from North America including Canada and the USA $(2,7,10)$, South America including Argentina and Brazil (2, 11, 12), and Europe including Czech Republic, Germany, Slovak Republic and Russia (2, 7, 13). Although the Fertile Crescent is considered to be the center of origin of wheat and most of its fungal pathogens $(14,15)$, to date no information is available on the genetic structure of natural populations of the pathogen in Iran.

\section{Objectives}

Knowledge of the genetic structure of $P$. triticirepentis in Iran is useful for improving wheat cultivars that are resistant to the pathogen populations. The relevant data helps to develope a breeding strategy to achieve durable disease resistance. Here, the genetic variability of $P$. tritici-repentis isolates originated from different wheat growing areas of Northern Iran was analyzed using Inter-Simple Sequence Repeat (ISSR) and Random Amplified Polymorphic DNA (RAPD) markers.

\section{Materials and Methods}

\subsection{Fungal Isolates and DNA Extraction}

During 2012-2013, the naturally infected wheat fields from different regions of Northern Iran were surveyed to collect the leaves having the typical symptoms of tan spot disease. The infected leaf samples were used to collect fungal isolates. Tan spot lesions were scraped using a sterile laboratory loop to collect $P$. tritici-repentis spores under stereomicroscope. The spores were scratched onto potato dextrose agar (PDA; potato 200 g.L $\mathrm{L}^{-1}$, dextrose 20 g.L-11, agar 15 g.L $\mathrm{L}^{-1}$ ) and allowed to germinate. After $10 \mathrm{~h}$, the germinated spores were individually isolated and transferred on new PDA plates as single spore isolate that incubated at $20^{\circ} \mathrm{C}$. The mycelial biomass were collected, transferred onto Eppendorf tube and kept at $-80^{\circ} \mathrm{C}$ for long term storage. Totally, $P$. tritici-repentis isolates $(\mathrm{n}=34)$ were collected (Table 1; Figure 1).

For DNA isolation, a scrape of each isolate growing on PDA was cut and transferred to liquid YGM (yeast extract 10 g.L $\mathrm{L}^{-1}$, dextrose 20 g.L $\mathrm{L}^{-1}$ ) and incubated on a rotating shaker at $100 \mathrm{rpm}, 20^{\circ} \mathrm{C}$ for 5 days.

Table 1. List of Pyrenophera tritici-repentis isolates and their sampling geographical coordinates

\begin{tabular}{|c|c|c|c|}
\hline Isolate code & Isolate name & Latitude & Longitude \\
\hline $\mathrm{P} 1$ & 91M10B1S2 & 36.74000 & 53.85333 \\
\hline P2 & 91M10B2S1 & 36.74000 & 53.85333 \\
\hline P3 & 91M3B2S1 & 36.63056 & 53.27139 \\
\hline P4 & 91M28B6S1 & 36.98750 & 54.97361 \\
\hline P5 & 91M8B13S2 & 36.71417 & 53.69583 \\
\hline P6 & 91M9B1S1 & 36.72694 & 53.75972 \\
\hline P7 & 91M11B2S1 & 36.74361 & 53.88194 \\
\hline P8 & 91M7B1S1 & 36.70194 & 53.61889 \\
\hline P9 & 91M51B1S1 & 36.71417 & 53.69417 \\
\hline P10 & 91M28B7S1 & 36.98750 & 54.97361 \\
\hline P11 & 91M13B2S1 & 36.76889 & 54.00583 \\
\hline P12 & 91M44B1S3 & 36.80667 & 54.14028 \\
\hline P13 & 91M43B2S1 & 36.82056 & 54.23111 \\
\hline P14 & 91M52B4S1 & 36.70139 & 53.57611 \\
\hline P15 & 91M43B6S1 & 36.82056 & 54.23111 \\
\hline P16 & 91M52B5S2 & 36.70139 & 53.57611 \\
\hline P17 & 91M15B7S1 & 36.80222 & 54.12361 \\
\hline P18 & 91M49B2S3 & 36.72444 & 53.74472 \\
\hline P19 & 91M15B4S1 & 36.80222 & 54.12361 \\
\hline P20 & 91M32B1S2 & 37.03083 & 55.02806 \\
\hline $\mathrm{P} 21$ & 91M15B6S2 & 36.80222 & 54.12361 \\
\hline $\mathrm{P} 22$ & 91M3B5S1 & 36.63056 & 53.27139 \\
\hline $\mathrm{P} 23$ & 91M6B2S1 & 36.69694 & 53.50806 \\
\hline P24 & 91M32B4S1 & 37.03083 & 55.02806 \\
\hline P25 & 91M32B6S1 & 37.03083 & 55.02806 \\
\hline P26 & 91M32B7S1 & 37.03083 & 55.02806 \\
\hline P27 & 91M32B8S3 & 37.03083 & 55.02806 \\
\hline P28 & $91 \mathrm{M} 32 \mathrm{~B} 5 \mathrm{~S} 1$ & 37.03083 & 55.02806 \\
\hline P29 & 91M11B3S1 & 36.74361 & 53.88194 \\
\hline P30 & 91M11B6S1 & 36.74361 & 53.88194 \\
\hline P31 & 91M10B4S1 & 36.74000 & 53.85333 \\
\hline P32 & 91M3B4S1 & 36.63056 & 53.27139 \\
\hline P33 & 91M3B5S1 & 36.63056 & 53.27139 \\
\hline P34 & 91M7B1S1 & 36.70194 & 53.61889 \\
\hline
\end{tabular}




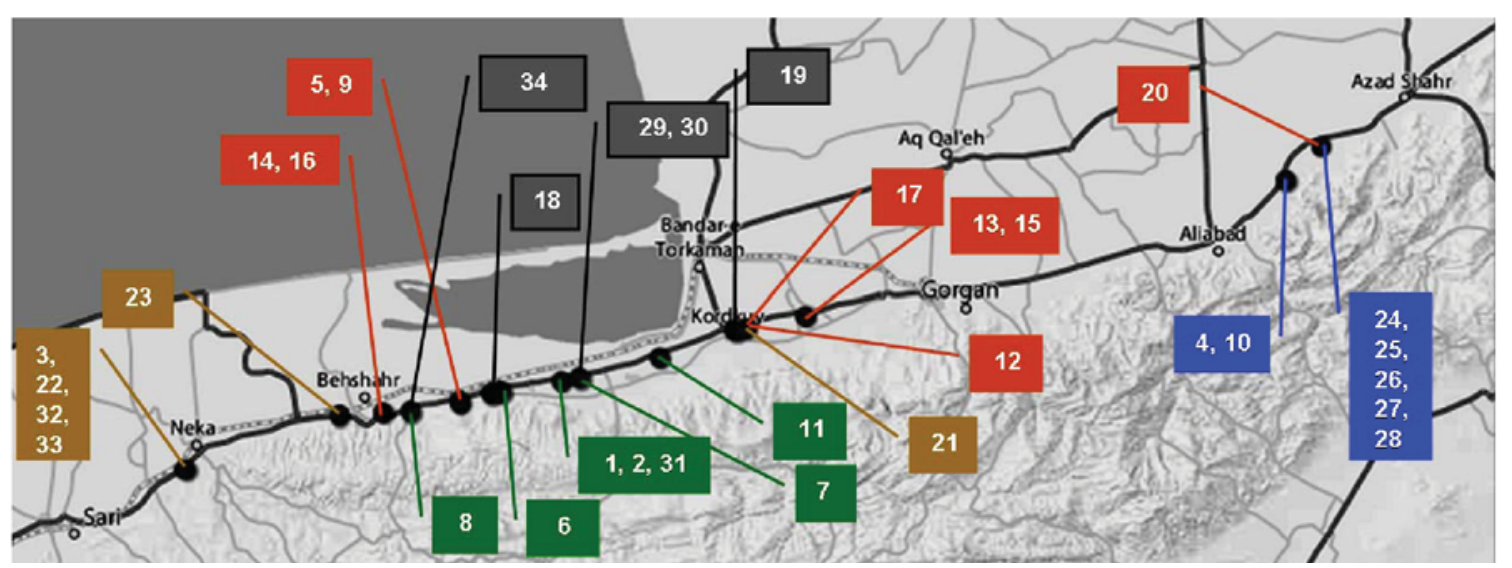

Figure 1. Sampling locations of Pyrenophora tritici-repentis isolates from Mazandaran and Golestan provinces based on GPS coordinates. The numbers showed in each box correspond to isolate codes as indicated in the Table 1

Table 2. Polymorphism and PIC values of ISSR and RAPD markers used for genetic diversity of 34 Pyrenophera tritici-repentis isolates

\begin{tabular}{cccccc}
\hline Marker & Primer names & $\begin{array}{c}\text { No. of ampli- } \\
\text { fied bands }\end{array}$ & $\begin{array}{c}\text { No. of poly- } \\
\text { morphic bands }\end{array}$ & polymorphism \% & PIC value \\
\hline \multirow{4}{*}{ ISSR } & UBC807 & 10 & 9 & 90 & \\
\hline & UBC815 & 15 & 10 & 67 & 0.49 \\
& UBC816 & 16 & 9 & 56 & 0.43 \\
& UBC818 & 14 & 7 & 50 & 0.39 \\
& UBC828 & 10 & 9 & 90 & 0.35 \\
& UBC880 & 17 & 9 & 53 & 0.36 \\
& UBC874 & 16 & 8 & 50 & 0.31 \\
& UBC822 & 14 & 6 & 42 & 0.27 \\
& & & & & \\
RAPD & OPC20 & 10 & 7 & 70 & 0.46 \\
& OPB7 & 11 & 10 & 91 & 0.48 \\
& OPA2 & 13 & 8 & 61 & 0.39 \\
& OPE10 & 12 & 9 & 75 & 0.44 \\
& OPF2 & 9 & 6 & 66 & 0.41 \\
& OPD6 & 11 & 8 & 72 & 0.43 \\
\hline
\end{tabular}

Fungal biomass was harvested by filtration through Miracloth, rinsed with distilled water and was finely grinded in liquid nitrogen and was subjected to DNA extraction according to SDS method (4). DNA concentration was estimated by spectrophotometer at a wavelength of $260 \mathrm{~nm}$.

\subsection{ISSR and RAPD Analysis}

For ISSR analysis, a set of 10 primers representing di-, tri-, tetra- and pentamer repeats was used (Table 2). RAPD assays were performed using 10 random 10 mer oligonucleotide primers (Table 2). PCR amplification was performed in $20 \mu \mathrm{L}$ reaction containing $1 \times$
PCR buffer, 30 ng sample DNA, $2.5 \mu \mathrm{M}$ primer, 200 $\mu \mathrm{M}$ of each dNTP, $1.5-2.5 \mathrm{mM} \mathrm{MgCl}_{2}$ and 1.5 unit of Taq DNA polymerase (Cinnagene, Iran). All amplifications were carried out in an Eppendorf thermocycler as follow: $94^{\circ} \mathrm{C}$ for $3 \mathrm{~min}$, followed by 35 cycles of denaturation at $93^{\circ} \mathrm{C}$ for $45 \mathrm{~s}$, annealing at optimum $\mathrm{Tm}$ for $45 \mathrm{~s}$, and extension at $72^{\circ} \mathrm{C}$ for $90 \mathrm{~s}$. A final extension cycle at $72^{\circ} \mathrm{C}$ for $10 \mathrm{~min}$ was also included. PCR products were separated on $1.2 \%$ agarose gels, stained with ethidium bromide and scored for the presence (1) or absence (0) of bands.

Nei's genetic distance (16) was determined among the isolates and used for cluster analysis by UNJ (Un- 
weighted Neighbor Joining) method as described previously (17). The fit of dendrograms obtained were checked by bootstrapping using 100 replications. NTSYS ver 2.02 (18) and DARwin ver 5.0 (19) were used for clustering. Mantel statistic was used to compare the dissimilarity matrices through NTSYS software. Polymorphic information content (PIC) values were calculated for each ISSR and RAPD primers according to the formula: $\mathrm{PIC}=1-\Sigma\left(P_{i j}\right)^{2}$, where $P_{i j}$ is the frequency of the $i^{\text {th }}$ pattern revealed by the $j^{\text {th }}$ primer summed across all patterns revealed by the primers (20).

\section{Results}

ISSR analysis of $34 P$. tritici-repentis isolates revealed distinct scorable fragments per primer and in total, 112 polymorphic and monomorphic bands were obtained using eight primers (Table 2). The number of amplified fragments varied from 10 to 17 , with an average 14 bands per primer. Out of 112 bands, 67 bands were polymorphic and the polymorphism percentage averaged to 0.59 across all the isolates. Maximum number of polymorphic bands (10 out of 15 bands) was obtained for UBC815. The average PIC value was 0.38 , ranging from 0.27 to 0.49 . The highest PIC value was obtained by UBC807 (0.49; Table 2).

For RAPD, only primers (6 primers) that exhibited

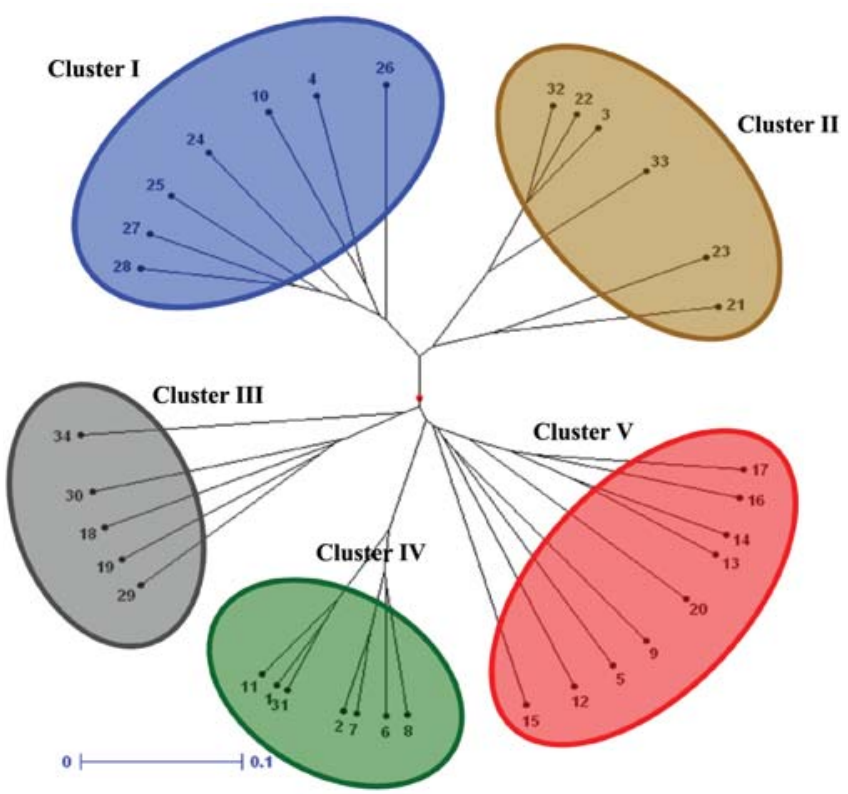

Figure 2. Dendrogram of Pyrenophora tritici-repentis isolates drawn using Un-weighted Neighbor Joining algorithm. Five major clusters are identified based on the dissimilarity matrix data developed by combined ISSR and RAPD markers unambiguous and reproducible banding patterns were selected for genetic similarity and cluster analysis. A total of 66 bands were detected in $34 P$. tritici-repentis isolates via RAPD. Out of which 48 were polymorphic (Table 2). Number of polymorphic bands were ranged from 6 (OPF2) to 10 (OPB7) with an average of 8 bands per primer. PIC values ranged from 0.39 to 0.48 , with an average value of 0.43 per primer (Table 2).

A dendrogram was constructed based on unweighted neighbor-joining method using the combined data of the two sets of molecular markers that revealed five distinct clusters among the $34 \mathrm{P}$. tritici-repentis isolates (Figure 2). Cophenetic coefficient was considered acceptable in two molecular markers types (ISSR=0.81; RAPD $=0.88$ ), indicating good fit for clustering. Cluster I consisted of 6 isolates that 5 of which collected from East Mazandaran and isolate P21 from Kordkuy, Golestan province (Figure 1). Cluster II had seven isolates, all collected from East Golestan. The isolate P20 was the only isolate that was collected from this region, but grouped in cluster V. Cluster III consisted of five isolates that were originated from a region between Behshar and Kordkuy. Cluster IV consisted of seven isolates that was collected from the same region, but was closely related to cluster III. The most disperse cluster was cluster $\mathrm{V}$ including nine isolates that were collected from different geographical regions (Figure 2). Isolate P20 that was collected from East of Golestan province grouped in this cluster.

\section{Discussion}

The level of genetic diversity within fungal populations is mainly attributed to several major factors including sexual recombination, mutation rate, gene flow, migration and selection pressure (8). P. triticirepentis is a homothallic wheat pathogen that reproduces both sexually and asexually. Sexual reproduction occurs on wheat stubble producing ascospores that are generally thought to be the source of primary inoculum. Asexual reproduction occurs in several cycles during the growing season (21). Sexual recombination in nature is likely the reason for high level of genetic variability among $P$. tritici-repentis isolates (10). Furthermore, P. tritici-repentis is seed borne. Therefore, fungal inoculums can travel long distances and disperse over long distances (7). ISSR and RAPD molecular markers were used to determine the level of genetic diversity of $P$. tritici-repentis isolates collected from different wheat growing areas of Northern Iran. A high level of genetic variability among Iranian $P$. tritici-repentis isolates was identified. The results from the 
cluster analysis indicated that the genetic similarity among the Iranian P. tritici-repentis isolates could be partly explained by geographic origin. Leisova et al. (7) showed that the genetic similarity among the isolates of P. tritici-repentis from Czech Republic, Slovak Republic, Russia, Canada, USA and Argentina could be partly explained by race classification, host species, geographical origin and the sampling year (7). Lepoint et al. (22) studied the genetic diversity of the mating type and toxin production genes in $P$. tritici-repentis. The phylogenetic analysis of the MAT locus revealed two distinct groups, unlinked to geographical origin or ToxA profile (22). Likewise, clustering of $P$ triticirepentis isolates from Russia, Germany, and the Czech Republic showed that groups of isolates from Bashkiria, Dagestan and North Osetia were separated from others and might be considered as different geographical populations (13). Nevertheless, no clear differentiation between isolates from other sites was revealed (13). In contrast, Santos et al. (11) showed that although the Brazilian isolates of $P$. tritici-repentis had a high level of polymorphisms, no correlation between RAPD data and geographical origins was identifiable. Likewise, Friesen et al. (2) also found that the worldwide population of $P$. tritici-repentis isolates had no genetic grouping of pathotypes or grouping for geographic location. Similarly, Singh and Hughes (10), showed that all isolates had unique banding patterns. However, clustering of isolates was independent of their race designation or geographical origin (10). Moreno et al. (12) identified intraspecific variability within $P$. tritici-repentis isolates, but they could not establish a relationship between this variability and the geographical regions and/or wheat cultivars from where $P$. tritici-repentis isolates were obtained (12). They proposed that the occurrence of the sexual state and long distance dispersal of inoculums could have contributed to pathogenic and genetic variability independent of geographic region (12).

Iran located in Fertile Crescent that is considered the centre of origin of most Triticum species and their fungal pathogens (14). Accordingly, the relatively high level of differentiation observed among the Iranian $P$. tritici-repentis isolates is something that one can expect. Wheat and P. tritici-repentis have been around for thousands of years. Therefore, genetic drift have had greater chance to operate, as opposed to other parts of the world where $P$. tritici-repentis was found not long time ago. The relatively distinct gene pools for the $P$. tritici-repentis isolates collected from North of Iran may also suggest that migration events rarely occurred among these populations. It is possible that the relative abundance of asexual- over sexual reproduction within each geographical region may lead to clonal and local populations that are distinctly different from other populations.

Although limited number of Iranian isolates and limited number of molecular markers were used, this study paved the road for future investigation by providing valuable information on the genetic diversity of Iranian population of $P$. tritici-repentis. A larger number of isolates including those that are collected from more diverse regions in Iran from wheat and its wild relatives as well as a global panel of $P$. tritici-repentis isolates might be needed to have a comparative analysis. It has been shown that fungal isolates from the Middle East where both hosts and their pathogens are co-evolved, had significantly higher gene diversity than populations in America and Europe (23). This issue for $P$. tritici-repentis populations remains to be addressed in future.

\section{References}

1. Lamari L, Strelkov SE. The wheat/Pyrenophora tritici-repentis interaction: progress towards an understanding of tan spot disease. Can J Plant Pathol. 2010;32(1):4-10. DOI: 10.1080/07060661003594117

2. Friesen TL, Ali S, Klein KK, Rasmussen JB. Population genetic analysis of a global collection of Pyrenophora triticirepentis, causal agent of tan spot of wheat. Phytopathology. 2005;95(10):1144-1150. DOI: 10.1094/PHYTO-95-1144

3. Bockus W, Shroyer J. The impact of reduced tillage on soilborne plant pathogens. Annu Rev Phytopathol. 1998;36(1): 485-500. DOI: 10.1146/annurev.phyto.36.1.485

4. Rajabpour M, Mehrabi R, Torabi M, Ebrahimi A. Distribution and frequency to toxin producing genes (ToxA and ToxB) in populations of Pyrenophora tritici-repentis, the causal agent of wheat tan spot in North of Iran. Seed Plant J. 2014; 30(1):73-83.

5. Chen RS, McDonald BA. Sexual reproduction plays a major role in the genetic structure of populations of the fungus Mycosphaerella graminicola. Genetics. 1996;142(4):11191127.

6. Linde CC, Zhan J, McDonald BA. Population structure of Mycosphaerella graminicola: From lesions to continents. Phytopathology. 2002;92(9):946-955. DOI: 10.1094/PHYT O.2002.92.9.946

7. Leisova L, Hanzalova A, Kucera L. Genetic diversity of Pyrenophora tritici-repentis isolates as revealed by AFLP analysis. J Plant Pathol. 2008;90(2):233-245. DOI: 10.1111/j. 1439-0434.2005.01019.x

8. McDonald BA. The population genetics of fungi: Tools and technique. Phytopathology. 1997;87:448-453. DOI: 10.1094/ PHYTO.1997.87.4.448

9. McDonald BA, Linde C. Pathogen population genetics, evolutionary potential, and durable resistance. Annu Rev 
Phytopathol. 2002;40(1):349-379. DOI: 10.1146/annurev. phyto.40.120501.101443

10. Singh PK, Hughes GR. Genetic similarity among isolates of Pyrenophora tritici-repentis, causal agent of tan spot of wheat. J Phytopathol. 2006;154(3):178-184. DOI: 10.1111/j. 1439-0434.2006.01083.x

11. Santos AMPVd, Matsumura ATS, Van Der Sand ST. Intraspecific genetic diversity of Drechslera tritici-repentis as detected by random amplified polymorphic DNA analysis. Genet Mol Biol. 2002;25(2):243-250. DOI: 10.1590/S141547572002000200020

12. Moreno MV, Stenglein SA, Balatti PA, Perello AE. Pathogenic and molecular variability among isolates of Pyrenophora tritici-repentis, causal agent of tan spot of wheat in Argentina. Eur J Plant Pathol. 2008;122(2):239-252. DOI: 10.1007/s10658-008-9277-2

13. Mironenko N, Timopheeva E, Mikhailova L, Kopahnke D, Krämer I, Ordon F. Intraspecific genetic diversity of Pyrenophora tritici-repentis (Died.) Drechs. (Drechslera tritici-repentis[Died.] Shoem.) detected by random amplified polymorphic DNA assays. Arch. Phytopathol. Plant Prot. 2007;40(6):431-440. DOI: 10.1080/03235400600627965

14. Abrinbana M, Mozafari J, Shamsbakhsh M, Mehrabi R. Genetic structure of Mycosphaerella graminicola populations in Iran. Plant Pathol. 2010;59(5):829-838. DOI: 10.1111/j. 1365-3059.2010.02309.x

15. Stukenbrock EH, Banke S, Javan-Nikkhah M, McDonald BA. Origin and domestication of the fungal wheat pathogen Mycosphaerella graminicola via sympatric speciation. Mol
Biol Evol. 2007;24:398-411. DOI: 10.1093/molbev/msl169

16. Nei M. Analysis of gene diversity in subdivided populations. PNAS. 1973;70(12):3321-3323.

17. Perrier XF, A. Bonnot, F. Data analysis methods. In: Hamon P, Seguin M, Perrier X, Glaszmann J.C. (eds) Genetic Diversity of Cultivated Tropical Plants. Science Publishers, Enfield, Montpellier. 2003;p.43-76.

18. Rohlf FJ. NTSYS-pc numerical taxonomy and multivariate analysis system. Version 2.02. Exeter Publications Setauket, New York. 1998.

19. Perrier X, Jacquemoud-Collet JP. DARwin software. http://darwin.cirad.fr/darwin. 2006.

20. Botstein D, White RL, Skolnick M, Davis RW. Construction of a genetic linkage map in man using restriction fragment length polymorphisms. Am J Hum Genet. 1980;32(3):314.

21. Ciuffetti LM, Tuori RP. Advances in the characterization of the Pyrenophora tritici-repentis-wheat interaction. Phytopathology. 1999;89(6):444-449. DOI: 10.1094/phyto. 1999.89.6.444

22. Lepoint P, Renard ME, Legreve A, Duveiller E, and Maraite $\mathrm{H}$. Genetic diversity of the mating type and toxin production genes in Pyrenophora tritici-repentis. Phytopathology. 2010;100(5):474-483. DOI: 10.1094/phyto-100-5-0474

23. Zhan J, Pettway RE, McDonald BA. The global genetic structure of the wheat pathogen Mycosphaerella graminicola is characterized by high nuclear diversity, low mitochondrial diversity, regular recombination, and gene flow. Fungal Genet Biol. 2003;38(3):286-297. DOI: 10.1016/s1087-1845(02)00 538-8 